Ciência e Natura, Santa Maria v.38 n.2, 2016, Mai.- Ago. p. $952-965$

Revista do Centro de Ciências Naturais e Exatas - UFSM

ISSN impressa: 0100-8307 ISSN on-line: 2179-460X

\title{
CIÊNCIA'NATURA
}

\section{Relações entre o poder público e a vegetação urbana: implicações e benefícios}

\author{
Relation between Public Administration and Urban Vegetation : Implications and \\ benefits
}

\section{Lenise Xavier dos Santos e Victor Paulo Kloeckner Pires}

Universidade Federal do Pampa, RS, Brasil

lenisexsantos@yahoo.com.br e victor@sgnet-rs.com.br

2016-04-20 Aceitar 2016-04-24

\begin{abstract}
Resumo
Cidades de países subdesenvolvidos têm um processo de crescimento desordenado e com pouco planejamento, principalmente quanto a questões ambientais. Sabendo que a vegetação urbana é fundamental para a qualidade ambiental, o objetivo central deste trabalho é identificar as práticas de gestão ambiental direcionadas à vegetação urbana, desenvolvidas pelos gestores municipais de São Gabriel - RS. A coleta de dados foi realizada através de entrevistas com membros da gestão pública e os principais resultados evidenciam que os gestores públicos reconhecem a importância e os benefícios proporcionados pela vegetação urbana, principalmente se esta for composta por espécies nativas; o manejo da vegetação urbana ocorre principalmente de acordo com o Código Estadual Florestal embora o município em questão possua uma legislação própria voltada à vegetação urbana. Os mecanismos de preservação da vegetação urbana utilizados pela gestão pública municipal baseiam-se em fiscalizações e estudos detalhados das solicitações submetidas podendo ocasionar negativas quanto ao Licenciamento Ambiental de determinados empreendimentos, de acordo com o Código Florestal Estadual. Cabe destacar a necessidade de uma Secretaria, unicamente de Meio Ambiente, que possa acompanhar as atividades desenvolvidas pela administração municipal e as que envolvam o meio ambiente, executadas dentro do município em estudo.
\end{abstract}

Palavras-chave: Gestão pública. Gestão ambiental. Vegetação urbana

\begin{abstract}
Most cities located in underdeveloped countries present disorganized growth due to lack of planning, mostly regards environmental issues. Considering Urban Vegetation fundamental to keep and increase the positive aspects of the environment, the main objectice of this paper is identifying the environmental administration practices related to it, developed by Local Public Administration in Sao Gabriel-RS. Data was collected from interviewing members of the Municipality who recognized the importance and benefits of Urban Vegetation especially when native species are preserved - Urban Vegetation handling mainly follow specifications listed on Codigo Estadual Florestal (State Law), even though there is a local legislation on that subject. The mechanisms to preserve this kind of vegetation are based on checking the impact of all enterprises requests that may have their environmental licence denied due to Codigo Florestal Estadual. We have concluded that an exclusive bureau to deal with environmental issues and supervise all the Municipality decisions regards Urban Vegetation would surely be more efficient.
\end{abstract}

keywords : Public administration ( municipality). Environmental administration. Urban vegetation 


\section{Introdução}

A forma como a sociedade está estruturada, no presente, faz com que as organizações se submetam a constantes mudanças em face de influencias que permeiam o ambiente. $\mathrm{O}$ cenário contemporâneo exige do poder público maiores competências para gerar e gerenciar melhorias de maneira contínua. Como resultado deste processo de adaptação, novas formas e/ou ferramentas de gestão acabam por ser desenvolvidas, como forma de readaptação à sustentabilidade.

Sabe-se que não é de hoje que existe, mundialmente, uma preocupação com a preservação e conservação com o meio ambiente. A formulação de leis ambientais em alguns países industrializados remete a década de 1970. No entanto somente nos primeiros anos do século XXI é que a temática gestão ambiental ganhou destaque como problemática acadêmica tornando-se objeto de estudo por pesquisadores internacionais ganhando, desta forma, um impulso significativo.

O alcance do termo gestão ambiental é enorme e seguidamente utilizado para nomear ações ambientais nos mais diversos espaços geográficos, exemplos disso são dados por Shigunov Neto, Campos, e Shigunov (2009, p. $14-$ 15), “... gestão ambiental de bacias hidrográficas, gestão ambiental de parques e reservas florestais, gestão de áreas de proteção ambiental, gestão ambiental de reservas de biosfera e outras tantas modalidades de gestão que incluam aspectos ambientais."
Shigunov Neto, Campos, e Shigunov (2009,

p. 17) definem gestão ambiental como sendo:

[...] o conjunto de atividades da função gerencial que determinam a política ambiental, os objetivos, as responsabilidades e os colocam em prática por intermédio do sistema ambiental, do planejamento ambiental, do controle ambiental e da melhoria do gerenciamento ambiental. Dessa forma, a gestão ambiental é o gerenciamento eficaz do relacionamento entre a organização e o meio ambiente.

Assim, o conjunto de projetos, programas e instrumentos que tem por finalidade proporcionar uma mudança organizacional e uma melhoria contínua é o universo de qualidade pelo qual a gestão ambiental é composta.

Além das tradicionais exigências do poder público, uma nova exigência se estabelece: a questão da temática ambiental, que se torna cada vez mais premente nas práticas gerenciais dos setores que têm o poder de administrar determinado local, nas diversas escalas geográficas - município, estado ou pais.

Compreende-se, dessa forma, que qualquer organização pública ou privada, independentemente do seu porte, deve buscar, permanentemente, uma melhoria ininterrupta da qualidade ambiental dos serviços, produtos e ambientes de trabalho.

Dentre as várias as razões que levam as empresas públicas ou privadas a praticar procedimentos gerenciais ambientalmente corretos, destaca-se: ( I ) crescente limitação de recursos naturais, seja por contínua utilização, seja por 
exaustão e degradação, sujeitos de atividades públicas ou privadas, o que o torna caros e também mais protegidos por legislações; ( II ) elevado custo de bens naturais, disponibilizados pela natureza a altos custos; ( III ) aumento dos índices populacionais, principalmente, nos países menos desenvolvidos, grande número populacional pressiona os recursos naturais; ( IV ) crescente exigência da legislação ambiental, que se traduz em uma maior cuidado com o ambiente; ( V ) pressões públicas locais, nacionais e/ou internacionais que exigem responsabilidades ambientais por parte das empresas públicas ou privadas; ( VI ) taxas financeiras e valores de apólices mais baixos, disponibilizados por seguradoras, financiadores e bancos à empresas que adotam medidas ambientais saudáveis; ( VII ) Sociedade e organizações nãogovernamentais cada vez mais exigente e crítica quanto a danos ambientais resultantes de atividades empresariais; ( VIII ) crescente pressão por parte de consumidores, que preferem produtos desenvolvidos quem condições ambientais saudáveis; (IX) imagem de empresas ambientalmente saudáveis é mais aceita por autoridades públicas, fornecedores, consumidores e acionistas; ( $X$ ) acionistas priorizam empresas que primam pela responsabilidade ambiental, preferindo investir nestas empresas (Shigunov Neto, Campos, \& Shigunov, 2009).

Assim, pode-se afirmar que gestão ambiental e Ciência Administrativa estão intrinsecamente ligadas, sendo a gestão ambiental considerada uma área do conhecimento desta ciência.
Shigunov Neto, Campos, e Shigunov (2009, p. 11) chamam atenção para:

A partir do momento em que as questões ambientais passaram a ser preocupação cada vez maior nas organizações, deslocando-se da função de proteção para se tornarem uma função administrativa, a gestão ambiental deixou de ser um tema da "moda" para ingressar na Ciência Administrativa, enquanto importante área de conhecimento.

De posse do conhecimento de que o principal agente transformador do espaço geográfico é o elemento humano, observa-se uma significativa diminuição, e por vezes até a inexistência de espaços constituídos por elementos naturais em meio urbano.

Em estudos que se referem à análise do meio ambiente e sua qualidade, é dada uma grande ênfase à vegetação, considerada como representativa das inter-relações entre o clima, solos e a influência humana. Informações sobre a vegetação são consideradas essenciais no desenvolvimento de um sistema de informações, devido a sua influência sobre o manejo dos recursos, e a interação com os outros atributos da paisagem, uma vez que pode ser considerada como um indicador das características desses atributos (RITERS et al., apud BOHRER, 2000).

DIAS. G. F. (2009, p. 147) é enfático ao afirmar que:

Sem a proteção assegurada com a vegetação, as águas das chuvas carregam a terra do solo (areia, argila e matéria orgânica, principalmente) para o leito dos rios, tornando-os mais rasos, causando as inundações e seus prejuízos. 
Este autor, ainda completa que "A retirada da vegetação nativa de uma região é uma das ações humanas que agride mais profundamente a natureza." (Dias. G. F. 2009, p. 147)

Assim, considera-se que para determinado espaço urbano apresentar uma satisfatória qualidade ambiental, é necessário, uma composição paisagística que privilegie a vegetação; compreendida aqui, desde um simples gramado até as mais frondosas espécies arbóreas (GOMES e SOARES, 2004). Logo, atribui-se a vegetação urbana um dos papéis mais importantes da qualidade ambiental no espaço urbano.

Com o transcorrer dos anos e o crescimento populacional atingindo características de uma progressão geométrica e a consequente necessidade de aumentar os espaços na qual estas atividades se estabelecem somados à característica de cidades de países subdesenvolvidos aumentarem de forma desestruturada, com pouco planejamento e estes espaços requerem do poder público um olhar mais preocupado com a elaboração e manutenção de espaços que promovam uma qualidade de vida, pois esta é frequente mente deixada de lado frente a uma preocupação apenas de apenas funcionais. (Almeida \& Rigolin, 2014).

A falta de planejamento urbano, juntamente com o crescimento desordenado nas cidades dos países em desenvolvimento, entre eles o Brasil, conferiu à população e aos planejadores uma atenção a vegetação, como componente indispensável ao espaço urbano. A arborização ganhou um destaque mais expressivo, pois passou a ser vista nas cidades como um importante elemento natural agindo como reestruturador do espaço urbano, pois as áreas mais arborizadas apresentam uma semelhança quanto às condições ambientais normais.

Inúmeros são os fatores que fazem com que as ações humanas atuem como agentes nos sistemas naturais; entre eles, o crescimento populacional; e a forma como surgem, crescem e são organizadas as cidades. Dito isso, pode-se afirmar que a vegetação urbana faz parte de um ecossistema composto pela interação entre sistemas naturais e sistemas antropogênicos. No entanto, não pode-se deixar de salientar que a expansão humana desordenada causa um processo drástico de fragmentação das áreas naturais (Santos, 2008).

Foi lentamente que a vegetação conquistou espaço nos centros urbanos, não apenas em decorrência da monotonia das cidades, mas também das necessidades ambientais decorrentes da expansão urbana e seus problemas.

Quanto a este princípio da consciência da necessidade de arborização nas cidades brasileiras, Marx (apud GOMES e SOARES, 2003) nos diz que:

A arborização e o ajardinamento dos espaços públicos principia na segunda metade do século passado, época em que se difunde como nova exigência pelo mundo. Há poucas gerações, portanto, que as plantas passaram a ornar e amenizar nossas ruas e praças. Além dos jardins comuns, raros e criados apenas nas cidades principais, a imagem urbana desconhecia árvores e canteiros nas vias e nos largos. De tratamento muito pobre, estes conheciam a sombra dos beirais e de uma ou outra árvore plantada por trás dos muros de algum terreno particular. $\mathrm{O}$ que pode parecer hoje uma atmosfera árida e causticante ao sol do meio dia era então a expansão clara da vida não rural e muito menos sertaneja. As matas, os matos, os campos e as roças ficavam 
fora do perímetro urbano que guardava o chão limpo batido de terra. As plantas, as suas flores e frutos, fartos de toda redondeza só entravam na cidade para satisfazer a necessidade ou o gosto do dono de alguma propriedade.

Felizmente, com passar do tempo, a situação acima apresentada ganha outra proporção, ficando evidente que tal mudança de comportamento deve-se ao conhecimento que foi-se gradativamente adquirindo, pela população, dos benefício proporcionados, pela flora a um espaço urbano, principalmente aos grandes centros.

Pode-se afirmar que estes benefícios estão associados a composição atmosférica, equilíbrio solo-clima e poluição sonora. A vegetação atua em várias frentes no sentido de um conforto ambiental, pois ( I )purifica o ar por fixação de poeira e materiais residuais e pela reciclagem de gases através da fotossíntese, ( II ) regula a umidade e, temperatura do ar; ( III ) mantém a permeabilidade, fertilidade do solo e protege-o contra a erosão; e ( IV ) reduz os níveis de ruído servindo como amortecedor do barulho nas cidades. Consequentemente, entes benefícios ambientais trazem consigo benefícios psicólogos, uma vez que, segundo Gomes, M. A. S. e Soares, B. R. (2003, p. 21) “influenciam sobre o estado de ânimo dos indivíduos massificados com o transtorno das grandes cidades, além de propiciarem ambiente agradável para a prática de esportes, exercícios físicos e recreação em geral.", ficando evidente a estreia relação existente entre qualidade ambiental e qualidade de vida.
Há, ainda, os efeitos estéticos que por sua vez também trazem benefícios psicológicos, e quanto a estes efeitos, Hauser (apud GOMES e SOARES, 2003) cita que:

a vida em um quadro sem beleza tem uma influência nefasta no equilíbrio psíquico do homem, árvores verdes e gramados têm um efeito repousante para o espírito e desenvolvem no homem o gosto pelo belo. As emoções sentidas ante uma bela paisagem, de linhas bonitas, áreas verdes e água, estão entre as experiências mais fortes e mais enriquecedoras da personalidade.

Existe também o fato inegável de que a vegetação urbana acaba por agregar valor ao especo onde ela está inserida. Quanto a isto, Gomes e Soares (2003, p. 23) chamam atenção da seguinte forma:

A necessidade de uma distribuição mais igualitária de áreas verdes na cidade é destacada por vários autores, pois a localização destas, na maioria das vezes, está associada à especulação imobiliária. Assim, os espaços destinados a lazer, quer sejam parques e praças públicas, quando bem equipados, tornam as áreas em seu entorno mais valorizadas e, consequentemente, procuradas pela garantia de uma vida mais saudável devido aos diversos benefícios que esses espaços lhes oferecem.

A diversidade de plantas, no ambiente urbanizado, é surpreendente. DIAS. G. F. (2009, p. 29) afirma que "em um simples canteiro [...] podem ser encontradas dezenas de espécies.".

No entanto, mesmo com tantos benefícios ao ambiente e a saúde da população que habita os centros urbanos, Gomes e Soares (2003, p. 22) nos informam para a existência de:

“... um descaso e uma falta de interesse dos órgãos públicos a da própria população no 
sentido de se conhecer a importância da vegetação no espaço urbano. Assim sendo, torna-se imprescindível a que a população conheça e valorize os aspectos climáticos e biológicos que a vegetação desempenha, e não somente perceba a árvore como elemento decorativo na cidade."

Este descaso é oriundo, em grande parte do fato, que, para manter a presença de vegetação urbana, as prefeituras têm um gasto razoável: galhos e folhas caídas devem ser retirados constantemente, o plantio e sua manutenção dependem de pessoal e equipamento específico, e o vandalismo e outros riscos devem ser controlados (Santos, 2008).

Observa-se assim, que alguns cuidados têm que ser levados em consideração sobre o crescimento das árvores no meio urbano. É necessário observar que, para uma planta se desenvolver, é preciso que esta encontre um ambiente favorável ao seu crescimento. Há ainda uma necessidade de um manejo adequado para com as arvores no meio urbano, principalmente as de grande porte, uma vez que esta por estar em um ambiente artificial é inevitável seu contato com a fiação elétrica e/ou suas raízes atingirem encanamentos subterrâneos ou áreas asfaltadas. A falta de planejamento ou incorreta manutenção da vegetação urbana existente na maioria das cidades de médio ou grande porte é perceptível. Rocha (2006, p.27) salienta que: "Se mal implantada, a arborização urbana pode trazer alguns problemas, tanto para a infra-estrutura urbana quanto para as pessoas, tais como: confronto de árvores com fiações elétricas, encanamentos, calhas, calçamentos muros e rede pluvial."
Assim, para que as árvores desempenhem em sua plenitude suas funções e não se torne um problema para a população, nota-se a necessidade de uma legislação específica e uma fiscalização por parte do poder público para com esta vegetação. Com isso, observa-se a importância de adotar estratégias ambientais voltadas ao gerenciamento das cidades (Santos, 2008).

Com isso, espera-se do poder público, especialmente da esfera municipal, uma preocupação permanente com a vegetação urbana em que se perceba, claramente, um planejamento que promova o necessário desenvolvimento urbano aliadas a elaboração e manutenção espaços com floretas urbanas em especial espécies nativas.

Para que isto ocorra gestores lançam mão de uma, cada vez mais rica, legislação, voltada para a proteção e conservação do meio ambiente.

Os conflitos gerados por uma crescente concentração populacional que possui uma relação direta com modelos econômicos que comprometem o equilíbrio ecológico e a qualidade de vida vêm agregando demandas judiciais cada vez mais complexas envolvendo questões ambientais.

A integração de estudos ambientais com a legislação ambiental e os instrumentos de defesa do ambiente são bastante recentes. As relações existentes entre o homem e o meio, sempre foram objeto da ciência geográfica denominadas por estudos da sociedade e da natureza (Araújo, 2007). Hoje, os enfoques e metodologias são diferentes e oferecem a perspectiva de maior interação em as diversas áreas de conhecimento em torno das questões ambientais. 
As normas jurídicas que protegem o ambiente têm por objetivo, segundo Araújo (2007, p. 109):

... disciplinar a relação sociedade $X$ natureza, visando assegurar $\mathrm{o}$ direito de toda a sociedade ao meio ambiente ecologicamente equilibrado, tanto para as presentes quanto para as futuras gerações. Tais normas têm seu rebatimento físico-espacial, na medida em que os bens que compõem o seu ambiente objeto de proteção (solo, água, ar, atmosférico, flora, fauna e patrimônio sociocultural) são suporte material para a sobrevivência humana e tido como seus recursos.

A utilização destes recursos promove muitos conflitos que estão geograficamente localizados e tratados a partir de um padrão sociocultural promovido por uma demanda da sociedade, que, por sua vez, vive em um território, seja município, estado, país, região, lugarejo, bacia hidrográfica, etc. Isso justifica a legislação ambiental possuir níveis federal, estadual e municipal e ainda acordos internacionais, que extrapolam limites territoriais.

Segundo Fiorillo (apud Araújo 2007) os instrumentos de tutela ambiental estão classificados em dois grupos: "mecanismos não-jurisdicionais e os mecanismos jurisdicionais." Os mecanismos nãojurisdicionais dizem respeito aos espaços especialmente protegidos; tombamento; zoneamento; auditorias ambientais; licenças; estudo de impacto ambiental e relatório de impacto ambiental - EIA/RIMA; atuação do Poder Público, entre outras. Os mecanismos jurisdicionais referemse às ações judiciais, tanto as de procedimento comum quanto às ações judiciais coletivas, que são os meios processuais utilizados na apuração de responsabilidade por danos ambientais.

No que tange a legislação ambiental brasileira, seu marco é a Lei Federal nº. 6938, de 1981 (Araújo, 2007) que institui a Política Nacional do Meio Ambiente, onde estabelece que deve-se atribuir responsabilidade e obrigatoriedade a indenizar ou reparar os danos os responsáveis por danos causados ao ambiente.

A proteção judicial do ambiente, visto como um bem jurídico de uso do povo é exercida pela Ação Civil Pública Ambiental (Lei Federal no․ 7347 de 1985 (apud Araújo, 2007) e insere a proteção não apenas ao meio ambiente, mas também a danos a locais de valor artístico, estético, históricos, turístico e paisagístico.

Com a Constituição Federal de 1988, o Brasil passou a com mais um importante instrumento de proteção a uma ambiente saudável, quanto a isso, Araújo (2007, p. 107), nos dizem que:

O advento da Constituição Federal de 1988 deu um grande impulso à questão ambiental no Brasil, pois o combate a qualquer processo de degradação do ambiente tornou-se dever de todos os cidadãos e não apenas ao estado, sendo que os meios judiciais de proteção ambiental tornaram-se legítimos instrumentos para esse fim.

Estas três leis citadas anteriormente (Lei Federal nº . 6.938, de 31/08/1981; Lei Federal nº. 7.347 de 24/07/1985 e Constituição Federal de 05/10/1988) possuem enorme mérito, sendo consideradas três marcos da atual legislação ambiental e constituem grandes momentos na história das políticas ambientais no Brasil. A partir de 1988 “apresenta-se um cenário, marcado, pela democratização e 
descentralização decisórias e pela rápida disseminação da noção de desenvolvimento sustentável.". (Cunha \& Coelho, 2007). Vive-se hoje um momento em que organismos internacionais, organizações não-governamentais (ONGs), corporações passam a integrar tanto a elaboração quanto a implementação das políticas ambientais.

Quanto à legislação que protege a vegetação urbana, pode-se dizer que diversos municípios possuem legislação específica que protege este tipo de vegetação, principalmente quando estas espécies constituem-se em vegetação nativa, visando uma qualidade ambiental e consequentemente proporcionar uma qualidade de vida a população urbana.

O Código Florestal Brasileiro (Lei ㄲo 12.651 de 25/05/2012) ao delimitar as Áreas de Preservação Permanente cita a vegetação urbana como protegida quando trata-se de mata ciliar ou em torno de reservatórios artificiais, ao ainda vegetação presente em terrenos que possuem encostas de morros, no entanto pouco se manifesta quanto a presença de árvores dispersas pelas cidades.

Evidencia-se a existência de legislação municipal específica quanto a vegetação urbana em São Gabriel - RS (Lei oo. 1825/91) que regula o corte de árvores no perímetro urbano. No entanto, podese dizer que na Lei Orgânica deste município (que data de 04 de abril de 1990) muito pouco espaço o meio ambiente/vegetação recebe e, tampouco à remanescentes da fauna nativa dispostas nas vias públicas e nas propriedades públicas ou privadas. Nos poucos artigos destinados a ecologia e ao meio ambiente apenas atribui-se ao município proteger, controlar e fiscalizar as ações que comprometem o ambiente de acordo com a legislação estadual. Cabe citar ainda o Plano Diretor deste município que possui um plano de estratégia voltado ao ambiente natural inserido no meio urbano:

"A sustentabilidade do ambiente natural resulta da adequada negociação entre o desenvolvimento econômico e demográfico com a natureza e seus recursos. A Estratégia 4 descreve os princípios básicos desta negociação em duas escalas: uma de natureza regional trata do território da zona rural em suas características fisiográficas principais, vinculando as estratégias de desenvolvimento econômico às suscetibilidades ambientais; e em outra escala, da sede municipal, trata do meio urbano, envolvendo assuntos relacionados à infra-estrutura e ao uso e regeneração de recursos ambientais, alguns parcialmente degradados."

O Plano Diretor de São Gabriel - RS possui ainda, um Plano de Gestão Ambiental que tem por objetivo indicar diretrizes gerais a serem consideradas na elaboração de um Plano de Gestão Ambiental. A proposta apresenta ainda as diretrizes necessárias para a habilitação do município ao Sistema Integrado de Gestão Ambiental (SIGA). Isto dará ao município competência para realizar o licenciamento ambiental municipal no que se refere aos procedimentos administrativos, ao exercício do poder de polícia ambiental, ao intercâmbio de informações entre os órgãos componentes do Sistema Estadual de Proteção Ambiental (SISEPRA) e atualização e adequação das atividades de impacto local. (São Gabriel, 2008).

\section{Desenvolvimento do trabalho}




\subsection{Objetivos do Estudo}

Desta forma, este estudo tem como objetivo central identificar as práticas de gestão ambiental direcionadas à vegetação urbana, desenvolvidas pelo setor público do município de São Gabriel - RS, com o intuito de mantê-la preservada. Especificamente, os objetivos relacionam-se com a possibilidade de (a) verificar qual a importância que a gestão pública municipal desprende a vegetação urbana, com ênfase à flora nativa; (b) constatar como se dá o manejo da vegetação urbana no âmbito municipal pelo setor público; (c) identificar os mecanismos utilizados pela gestão pública em relação à preservação das espécies arbóreas presentes no município.

\subsection{Materiais e Métodos}

Para a consecução dos objetivos propostos neste estudo, definiram-se os métodos, o instrumento de pesquisa, assim como os procedimentos para coleta de dados. Utilizou-se o método de pesquisa tipo survey. Este, segundo Pinsonneault e Kraemer (1993), requer informações padronizadas do assunto estudado. Essas informações podem ser relativas a indivíduos, grupos, organizações ou comunidades. O principal meio de coleta de dados é por questões prédefinidas e estruturadas cujas respostas constituem o dado a ser analisado. É mais apropriado em questões centrais tipo "como e por que está acontecendo, o que, quanto e como". Também é definido como a obtenção de informações sobre características, ações ou opiniões de um grupo de pessoas, indicado como representante de uma população por meio de um instrumento, normalmente um questionário.

Ainda, segundo Pinsonneault e Kraemer (1993) e Trivinos (1992), classifica-se como pesquisa descritiva, pois visa identificar quais situações, eventos, atitudes ou opiniões são manifestadas em uma população, no caso deste trabalho, na organização. Considera-se que pesquisa descritiva seja a mais indicada quando se deseja obter as características de determinada população ou o estabelecimento de relações entre as variáveis. Uma de suas características mais significativas está na utilização de técnicas padronizadas de coleta de dados.

A pesquisa é de corte transversal, uma vez que os dados são coletados num dado momento no tempo, e não há intenção de avaliar/monitorar suas variações no decorrer do tempo, (GIL, 2010).

Quanto à coleta de dados, esta se valeu de dados primários, que são definidos como aqueles coletados especialmente para atender às necessidades da pesquisa (GIL, 2010). Foi utilizada a entrevista semi-estruturada. Para Gil (2010), esta técnica de coleta de dados deve ser guiada por uma relação de questões de interesse do investigador e que durante a entrevista podem surgir outras interrogações por parte do investigador, conforme as respostas do entrevistado. Este recurso foi utilizado especialmente nas entrevistas com os Secretários e alguns de seus assessores das Secretarias de Obras, Habitação, Urbanismo e Meio Ambiente e da Secretaria de Agricultura de São Gabriel - RS. O papel do entrevistador na entrevista 
semi-estruturada é centrar atenção em determinados tópicos, quanto aos entrevistados todos devem estar envolvidos em situações inerentes a investigação. A entrevista semiestruturada valoriza não somente a presença do investigador, como também oferece todas as perspectivas possíveis para que o informante alcance a liberdade e a espontaneidade necessárias, enriquecendo a investigação.

As entrevistas foram realizadas com horário agendado com os Secretários e assessores e técnicos das secretarias citadas. A entrevista foi realizada na sede das secretarias através de uma entrevista estruturada com nove (9) questões relacionadas com os objetivos da pesquisa. $\mathrm{O}$ Secretário de Obras, Habitação, Urbanismo e Meio Ambiente auxiliou e o responsável pelo Departamento de Meio Ambiente auxiliaram o desenvolvimento da pesquisa convidando os assessores e técnicos, entre eles aqueles que tivessem disponibilidade de tempo, por ocasião da coleta de dados. Foi possível obter oito (8) entrevistas.

\subsection{Resultados e análises dos dados coletados}

Desta forma, foi possível constatar-se que no que se refere a gestão ambiental, dentro das secretarias estudadas, esta se dá puramente por o Departamento do meio ambiente pertencer a Secretaria de Obras, Habitação, Urbanismo e Meio Ambiente - SOHU, uma vez que 37,5\% dos respondentes se referiam apenas ao pertencimento do referido departamento à SOHU. Outros 37,5\% afirmam que a Gestão Ambiental ocorre, uma vez que a SOHU é o órgão que realiza os licenciamentos. E os restantes responderam que a gestão ambiental ocorre ao ser observado com cautela as Áreas de Proteção Permanente - APP. Com isso, foi possível concluir que há um equívoco dentro das secretarias estudas, quanto ao conceito de Gestão Ambiental, pois, em vez de existir um planejamento voltado para o meio ambiente nas ações a serem desenvolvidas, há ações puramente de tentativas de contornos e cumprimento da legislação ambiental estadual existente para a SOHU desempenhar suas atribuições.

A importância da vegetação nativa foi reconhecida por $100 \%$ dos respondentes, sendo citado a necessidades da vegetação para a manutenção do clima local e global, e o cuidado com a vegetação nativa na hora de realizar um licenciamento ambiental. A vegetação exótica, também foi citada por $12,5 \%$ dos respondentes devido, principalmente à sua beleza ornamental.

As ações voltadas para a manutenção da vegetação nativa ocorrem na forma do cumprimento da Lei Municipal 1825/91, ao Código Estadual do Meio Ambiente - Lei no. 11520/00.

Através de legislação específica, o município regula o corte de árvores de quaisquer espécies de árvores no perímetro urbano sob o qual exerce sua jurisdição. Assim, a Lei no․ 1825/91, proíbe o corte de árvores, exceto em (I) casos em que haja ameaça a segurança patrimonial ou física do proprietário, seus dependentes e vizinhos; (II) impeça construções de prédios e desde que o projeto esteja devidamente aprovado pela Prefeitura; (III) 
espécies exóticas; (IV) mortas ou em decadência fisiológicas; e (V) ameace o patrimônio público, como é o caso de redes elétrica, telefônica, hidráulica e sanitária. Para o corte, é necessária a autorização, o que acontece mediante prévia inspeção. Da regra, se subsume que, aquele que não possuir a devida autorização, submete-se à multa.

Mesmo havendo legislação específica, o município de São Gabriel - RS utiliza, para regular as ações que envolvam o ambiente, a legislação estadual que Institui o Código Estadual do Meio Ambiente do Estado do Rio Grande do Sul e dá outras providências. E quanto a proteção da vegetação, observa, na lei $n^{\circ}$. 11520/00, principalmente o Art. 154 que diz o seguinte:

"A vegetação nativa, assim como as espécies da flora que ocorrem naturalmente no território estadual, elementos necessários do meio ambiente e dos ecossistemas, são considerados bens de interesse comum a todos e ficam sob a proteção do Estado, sendo seu uso, manejo e proteção regulados por esta Lei e demais documentos legais pertinentes."

Foi também mencionado a reposição florestal, que dá-se da seguinte forma, quando há a remoção de uma árvore nativa há o plantio de 15 novas mudas em local previamente estudado e autorizado. Foi também citado que, sempre que possível manter há um empenho para não remoção/preservação, porém esta frase, apenas verbalizada por um respondente, foi seguida da seguinte observação: “...se uma árvore não está causando algum impedimento ao desenvolvimento de alguma obra, ela é preservada." Há ainda a questão de que $25 \%$ responderam que tal ação não pertence às responsabilidades da secretaria na qual desempenha suas ações.

Quando do questionamento a respeito da existência de algum inventário das espécies arbóreas imunes ao corte, no município de São Gabriel - RS, a maioria dos respondentes afirma que a secretaria na qual estão desempenhando suas funções não possui; 12,5\% afirmaram que tal inventário corresponde às espécies nativas; e outros $12,5 \%$ responderam que sim, pois há as espécies que estão definidas em legislação.

A importância da vegetação urbana se verificou no momento em que maioria assim entende que é bastante importante, muito importante, ou que é de grande importância; 37,7\% citaram os diversos benefícios proporcionados pela vegetação urbana como qualificadores do solo, do clima, para os recursos hídricos, para o sombreamento, paisagismo, habitat de espécies animais. Outros 12,5 também citaram que vivenciam diariamente os benefícios de um local arborizado e florido. (Gomes \& Soares, 2003)

O planejamento das ações voltadas para a manutenção da vegetação urbana inseridas nas práticas tomadas pelas secretarias analisadas ocorre na forma de solicitações enviadas pela população para que se pratique o manejo, preocupando-se com as Áreas de Proteção Permanente e através dos serviços urbanos, como a poda, por exemplo. Também foi mencionado que, pelo fato da SOHU ser responsável pelo licenciamento ambiental, a torna parceira das secretarias responsáveis pela manutenção e ampliação da vegetação urbana, com replantio e criação de novos ambientes arborizados, 
essa observação foi exemplificada através da construção da Praça Bairro Vargas, que está em andamento e do projeto de revitalização da Praça Matriz (Praça Dr. Fernando Abbott). Obteve-se, também, a resposta de que a secretaria na qual o entrevistado desempenha suas funções quase não atua dentro da área urbana. E 25\% observaram que o município não possui projeto ou plano de arborização. Foi possível constatar que nem todos os entrevistados interpretaram da mesma forma o questionamento quanto ao planejamento das ações destinadas a manutenção da vegetação urbana dentro das praticas tomadas, por isso tantas respostas distintas.

No que se refere à existência de legislação específica que torne algumas espécies arbóreas imunes ao corte dentro do perímetro urbano de São Gabriel - RS, a maioria dos respondentes afirma seguir legislação estadual ou federal e foram citados como exemplos o Decreto $n^{\circ}$ 38355/98, que estabelece as normas básicas para o manejo dos recursos florestais nativos do Estado do Rio Grande do Sul de acordo com a legislação vigente; a Lei $n^{\circ}$ 7989/85 que Declara protegidas as florestas remanescentes do Estado do Rio Grande do Sul, nos termos do Código Florestal, e dá outras providências; e a Lei $\mathrm{n}^{\circ}$ 9519/92 que Institui o Código Florestal do Estado do Rio Grande do Sul e dá outras providências. $12,5 \%$ se referiram a Lei Municipal Lei Municipal $n^{\circ}$ 1825/91. Outros 12,5\% responderam haver legislação e que sempre solicita o encaminhamento aos técnicos responsáveis.

Sem exceção, os respondentes afirmaram reconhecer a importância da existência de uma legislação específica voltada para a proteção de espécies nativas no perímetro urbano de São Gabriel - RS e foi ressaltado que esta deve estar em contexto com as legislações estaduais e federais, foi ainda mencionado que no Plano Diretor deste município existem índices de taxas de ocupação e aproveitamento, além do recuo de jardim obrigatório.

De acordo com os respondentes, os mecanismos utilizados pelo poder público municipal para coibir a remoção da vegetação urbana protegida são avaliações de solicitações de poda/remoção e seguida de eventuais negativas para estas solicitações, vistorias, multas, ações no Ministério Público. As Leis $n^{\circ} 1825 / 91$ e o Código Estadual do Meio Ambiente Lei $n^{\circ}$. 11520/00 foram citadas como mecanismos de coibição por $25 \%$ dos entrevistados e 12,5\% responderam que a SOHU possui estrutura voltada ao Licenciamento Ambiental, usando de convênio firmado com a Fundação Estadual de Proteção Ambiental - FEPAM e fiscaliza em parceria a Patrulha Ambiental, e que possui ações de plantio e contribuições.

\section{Conclusões}

Sob a ótica da importância que a gestão pública municipal de São Gabriel - RS atribui a vegetação urbana e mais especificamente da vegetação nativa urbana, verificou-se que os gestores reconhecem os benefícios proporcionados pela flora nativa, bem como a importância desta inserida no meio urbano e, dentre elas, pode-se citar a qualidade do ar, manutenção do clima, manutenção das características do solo e 
manutenção de espécies animais que se utilizam deste tipo de vegetação e garantem um equilíbrio ecológico. A qualidade de vida proporcionada por um ambiente com espécies arbóreas não ficou de fora da lista de importância que os gestores empreendem a vegetação urbana.

O manejo da vegetação urbana dá-se no momento que a gestão pública municipal se vale de legislação estadual e municipal voltadas diretamente para a manutenção da vegetação urbana. Entre estas, é observada com mais ênfase o Código Florestal Estadual do Meio Ambiente. Constata-se, ainda, a existência de uma lei municipal que disciplina o corte de árvores de qualquer espécie no perímetro urbano - Lei $\mathrm{n}^{\circ}$. 1825/91. No entanto, apenas pequena parcela da administração pública municipal é conhecedora de tal legislação.

Os mecanismos voltados à preservação da vegetação urbana utilizados pela gestão pública municipal baseiam-se em fiscalizações, estudos detalhados das solicitações submetidas podendo ocasionar negativas quanto ao Licenciamento Ambiental de determinados empreendimentos, levando em conta o Código Florestal Estadual. Observa-se, também, no município de São Gabriel convênio firmado com a Fundação Estadual do Meio Ambiente e uma parceria com a Patrulha Ambiental que desemprenha ações de plantio.

Faz-se necessário, no município de São Gabriel - RS uma Secretaria de Meio Ambiente, uma vez que a este tem destinado, atualmente, apenas um Departamento de Meio Ambiente que pertence a Secretaria de Obras Habitação e Urbanismo. Ao ambiente não é destinado o papel de objeto principal, das hodiernas preocupações das cidades como um todo. É preciso, antes, que o município passe a valer-se de suas prerrogativas de ente público, legitimando práticas ambientais para que, legitimamente, passe ter ações que realmente o protejam ou que venham a favorecer as questões ambientais, uma vez que observou-se, claramente, que os gestores municipais planejam suas ações de modo, apenas, a não ferir o que diz a legislação que o protege, principalmente quando do desenvolvimento de alguma obra.

\section{Referências}

ALMEIDA, L. M. A. de \& RIGOLIN, T. B. Fronteiras da Globalização - o mundo natural e o espaço humanizado. 2ª . ed. São Paulo: Ática, 2014.

ARAÚJO, L. A de. Perícia Ambiental. in: CUNHA, S. B. da e GUERRA, A. J. T. A Questão Ambiental: Diferentes Abordagens. 3a․ Ed. Rio de Janeiro: Bertrand Brasil, 2007, p. 107 - 151.

BOHERER, C. B. da A. Vegetação, paisagem e o Planejamento do Uso da Terra. GEOgraphia. Ano II, no. 4, p. $103-120$.

BRASIL. Lei no. 9.795 de 27 de abril de 1999. Dispõe sobre a educação ambiental, institui a Política Nacional de Educação Ambiental e dá outras providências. Brasília. 1999.

CUNHA, L. H. e COELHO. M. C. N. Política e Gestão Ambiental. in: CUNHA, S. B. da e GUERRA, A. J. T. A Questão Ambiental: Diferentes Abordagens. 3 ${ }^{\text {a }}$. Ed. Rio de Janeiro: Bertrand Brasil, 2007, p. $43-79$.

DIAS, G. F. Atividades Interdisciplinares de Educação Ambiental. 2 ed. São Paulo: Gaia, 2006. 224p. 
GIL, A. C. Como Elaborar Projetos de Pesquisa. São Paulo. 5 Edição. Editora: Atlas. 2010.

GOMES, M. A. S. e SOARES, B. R. A Vegetação nos Centros Urbanos: Considerações sobre os Espaços Verdes em cidades Médias Brasileiras. Estudos Geográficas. Rio Claro: 2003. P. 19 - 29. Disponível em

HTTP//www.rc.unesp.br/igce/grad/geografia/revist ahtml. Acesso em: 01 fev. 2015.

PINSONNEAULT, A., KRAEMER, K. L. Survey research methodology in management information systems: an assessment, Journal of Management Information Systems, Automs, 1993.

PORTO, M. L. Os Campos Sulinos: sustentabilidade e manejo. In: Ciência \& Ambiente. UFSM. Fitogeografia do Sul da América. UFSM. n²4. Santa Maria: Pallotti, Jan/Jun 2002.

RIO GRANDE DO SUL. Decreto n. 38355, de 01 de abril de 1998. Estabelece as normas básicas para o manejo dos recursos florestais nativos do Estado do Rio Grande do Sul de acordo com a legislação vigente. Disponível em: <http://www.geocities.ws/>. Acesso em: Acesso em: 15 set. 2015.

RIO GRANDE DO SUL. Lei n. 7989, de 19 de abril de 1985. Declara protegida as florestas remanescentes do Estado do Rio Grande do Sul, nos termos do Código Florestal, e dá outras providências. Disponível em: $<$ http://www.silex.com.br/leis/Lei7989.html>. Acesso em: 15 set. 2015.

Lei n. 9519, de 21 de janeiro de 1992. Institui o Código Florestal do Estado do Rio Grande do Sul e dá outras providências. Disponível em: $<$ http://www.al.rs.gov.br/>. Acesso em: Acesso em: 15 set. 2015.

Lei n. 11529, de 03 de agosto de 2000. Institui o Código Estadual do Meio Ambiente do Estado do Rio Grande do Sul e dá outras providências. Disponível em: $<$ http://www.al.rs.gov.br/>. Acesso em: 15 set. 2015.
ROCHA, J. R. Cobertura vegetal em áreas urbanas: uma comparação entre três bairros do município de Santa Maria - RS. 2006. 65p. Trabalho de Conclusão (Graduação em Geografia) - Universidade Federal de Santa Maria, Santa Maria, 2006.

ROSS, J. L. S. (org) Geografia do Brasil, 5 ed. São Paulo: edusp. 2005.

SAINT-HILAIRE, A. Viajem ao Rio Grande do Sul (1820 - 1821). São Paulo, Belo Horizonte: Editora da Universidade de São Paulo, Livraria Itatiaia Editora Ltada, 1974.

SANTOS, L. X. O patrimônio natural tombado no município de Santa Maria (RS): Problematizando questões para a educação ambiental. 2008. 83p. Trabalho de Graduação (Graduação em Geografia Licenciatura Plena) - Universidade Federal de Santa Maria, Santa Maria, 2008.

SÃO GABRIEL. Lei Orgânica Do Município De São Gabriel, de 4 de abril de 1990. Disponível em: $<$ http://www.saogabriel.rs.gov.br/>. Acesso em: 16 set. 2015.

Lei n.1825, de 1991. Disciplina o corte de árvores de qualquer espécie no perímetro urbano e dá outras providências. São Gabriel, 1991.

Plano Diretor Desenvolvimento Urbano e Ambiental de São Gabriel. Porto Alegre, novembro de 2007. Disponível em: $<$ http://www.saogabriel.rs.gov.br/>. Acesso em: 16 set.2015.

SHIGUNOV NETO, A., CAMPOS, L. M. de S. e SHIGUNOV, T. Fundamentos da Gestão Ambiental. 1ed. Rio de Janeiro: Ciência Moderna, 2009. 295p.

TRIVINOS, A. Introdução a Ciências Sociais. São Paulo. Editora Atlas. 1992. 